\title{
Erratum to: Barriers and traps: great apes' performance in two functionally equivalent tasks
}

\author{
Gema Martin-Ordas $\cdot$ Franka Jaeck $\cdot$ Josep Call
}

Published online: 13 September 2013

(c) Springer-Verlag Berlin Heidelberg 2013

Erratum to: Anim Cogn (2012) 15:1007-1013

DOI 10.1007/s10071-012-0504-z

In the original publication, the family name of the second author was incorrectly published as Jaek. The correct family name of the author is Jaeck.

The online version of the original article can be found under doi:10.1007/s10071-012-0504-z.

G. Martin-Ordas · F. Jaeck · J. Call

Max Planck Institute for Evolutionary Anthropology,

Leipzig, Germany

G. Martin-Ordas ( $\square)$

Department of Psychology, Center on Autobiographical

Memory Research-CON AMORE, Aarhus University,

Aarhus, Denmark

e-mail: ordas@eva.mpg.de; ordas@psy.au.dk 